\title{
Respiratory failure associated with the lipodystrophy syndrome in an HIV-positive patient with compromised lung function
}

\author{
Natasha Press MD FRCPC ${ }^{1}$, Valentina Montessori MD FRCPC ${ }^{1}$, Tony R Bai MD FRCPC ${ }^{2}$, \\ Julio Montaner MD FRCP ${ }^{3}$ \\ Divisions of ${ }^{1}$ Infectious Diseases and ${ }^{2}$ Respirology, St Paul's Hospital, \\ University of British Columbia; ${ }^{3} \mathrm{BC}$ Centre for Excellence in HIV and AIDS, \\ St Paul's Hospital, Vancouver, British Columbia
}

\begin{abstract}
N Press, V Montessori, TR Bai, J Montaner. Respiratory failure associated with the lipodystrophy syndrome in an HIV-positive patient with compromised lung function. Can Respir J 2001;8(4):279-282.

Protease inhibitors, used as treatment in human immunodeficiency virus (HIV) infection, are associated with a syndrome of peripheral lipodystrophy, central adiposity, hyperlipidemia and insulin resistance. An HIV-positive patient with chronic obstructive pulmonary disease is presented who developed the lipodystrophy syndrome that is associated with the use of protease inhibitors. It is postulated that the lipodystrophy syndrome further compromised his lung function, leading to respiratory failure. Patients who have pulmonary disease and are taking protease inhibitors require monitoring of clinical status and pulmonary function tests.
\end{abstract}

Key Words: Acquired immunodeficiency syndrome; Human immunodeficiency virus; Lipodystrophy; Protease inhibitors; Respiratory failure
Insuffisance respiratoire associée au syndrome de lipodystrophie chez un patient VIH-positif

RÉSUMÉ : Les inhibiteurs de la protéase utilisés pour le traitement de l'infection au VIH (virus de l'immunodéficience humaine) sont associés à un syndrome de lipodystrophie périphérique, d'adiposité centrale, d'hyperlipidémie et d'insulinorésistance. Nous présentons ici le cas d'un patient VIH-positif atteint de bronchopneumopathie obstructive chronique qui a développé un syndrome de lipodystrophie associée à l'utilisation d'inhibiteurs de la protéase. On suppose que le syndrome de lipodystrophie a détérioré la fonction pulmonaire, entraînant l'insuffisance respiratoire. Il faut surveiller étroitement l'état clinique et la fonction respiratoire des patients qui souffrent de maladie pulmonaire et qui prennent des inhibiteurs de la protéase.
$\mathrm{T}$ The use of highly active antiretroviral therapy (three drugs or more) has led to a decrease in human immunodeficiency virus (HIV)-related morbidity and mortality com- pared with patients taking only mono- or dual therapy. Protease inhibitors are recommended as a component of this combination therapy, and have been shown to provide both 

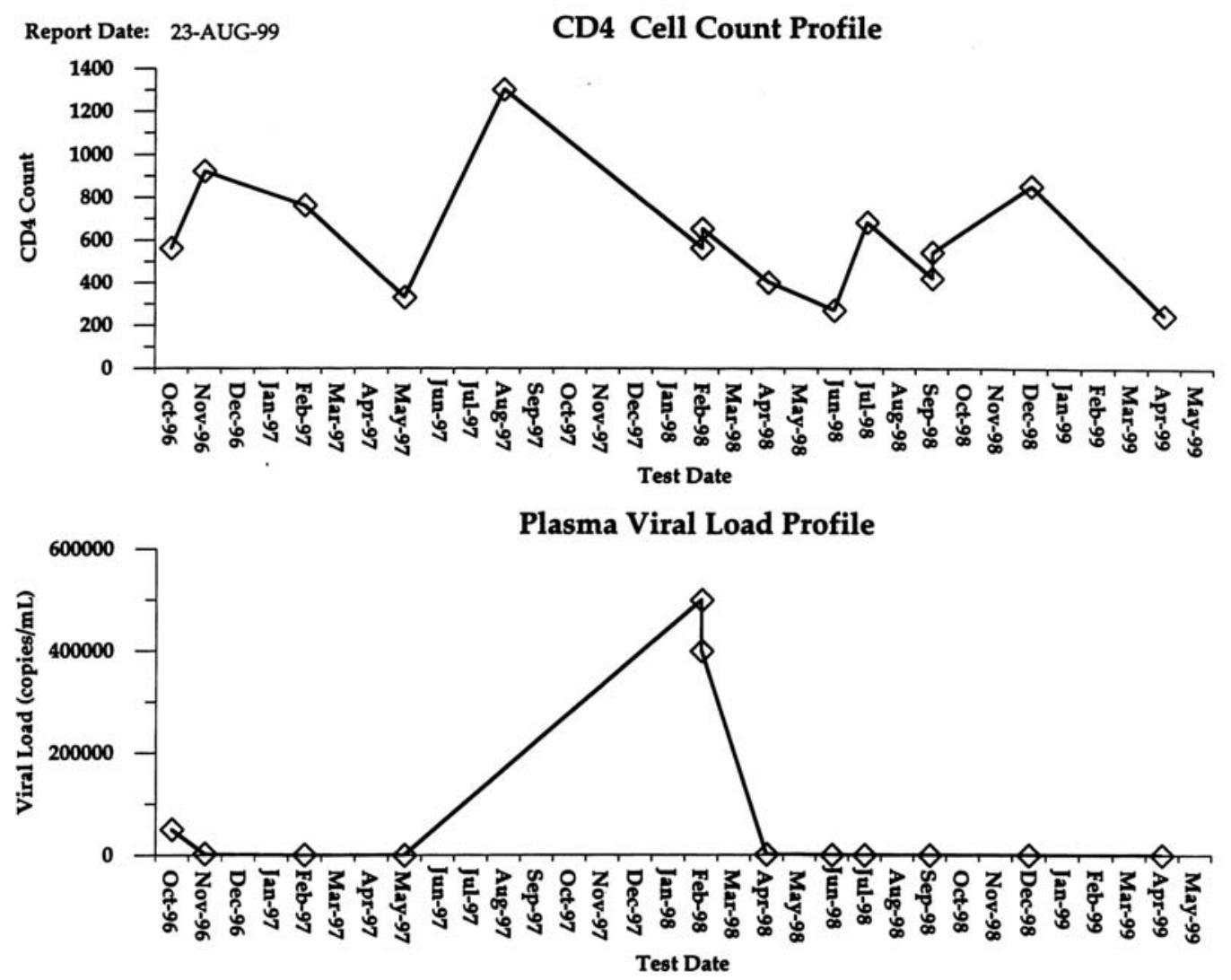

\section{Antiretroviral Drug Profile}

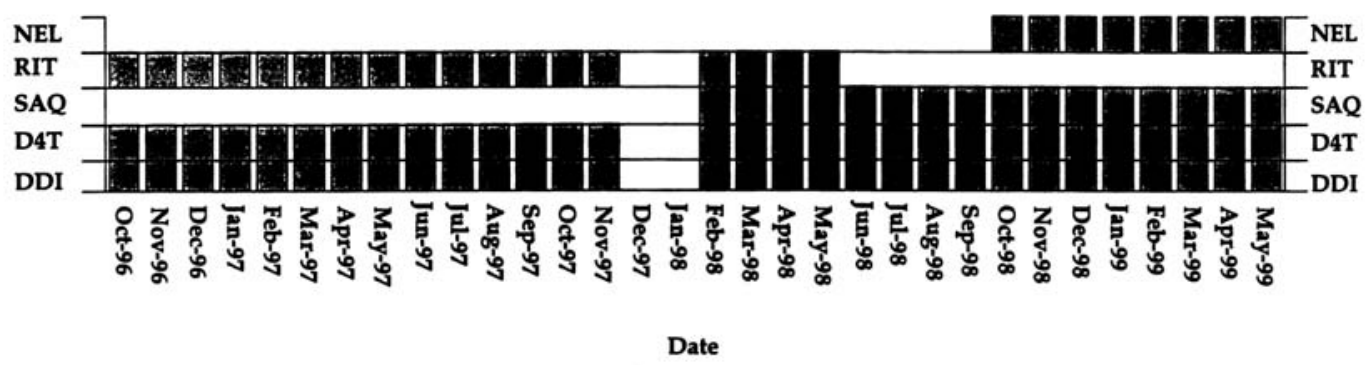

Figure 1) Immunological and virological response to antiretroviral combinations in a human immunodeficiency virus-positive 41 -year-old man in October 1996, when protease inhibitors were initiated. D4T Stavudine; DDI Didanosine; NEL Nelfinavir; RIT Ritonavir; SAQ Saquinavir

virological and clinical benefits, such as a decreased rate of opportunistic infections and acquired immunodeficiency syndrome (AIDS)-related deaths (1). However, use of protease inhibitors is associated with morphological and metabolic alterations including peripheral lipodystrophy, central adiposity, breast hypertrophy, hyperlipidemia and insulin resistance. These alterations are referred to collectively as the lipodystrophy syndrome, but can be divided into lipoatrophy (subcutaneous fat loss in limbs, glutei and face), lipoaccumulation (buffalo hump, bull neck, abdominal adiposity), mixed lipoatrophy and lipoaccumulation, and metabolic abnormalities (hyperglycemia, hypertriglyceridemia, hypercholesterolemia) (2). Previous studies have reported rates of protease inhibitor- induced lipodystrophy syndrome as high as $85 \%$. However, severe lipodystrophy is seen in $10 \%$ to $15 \%$ of patients after several years of treatment (3).

We present an HIV-positive patient with chronic obstructive pulmonary disease (COPD) who developed the lipodystrophy syndrome associated with protease inhibitors. We speculate that his central adiposity and lipodystrophy further compromised his lung function, leading to respiratory failure and death.

\section{CASE PRESENTATION}

In 1994, a 41-year-old man presented with Pneumocystis carinii pneumonia (PCP). He was found to be HIV-positive (ELISA and Western blot) and had a CD4 count of 40 cells/ L 


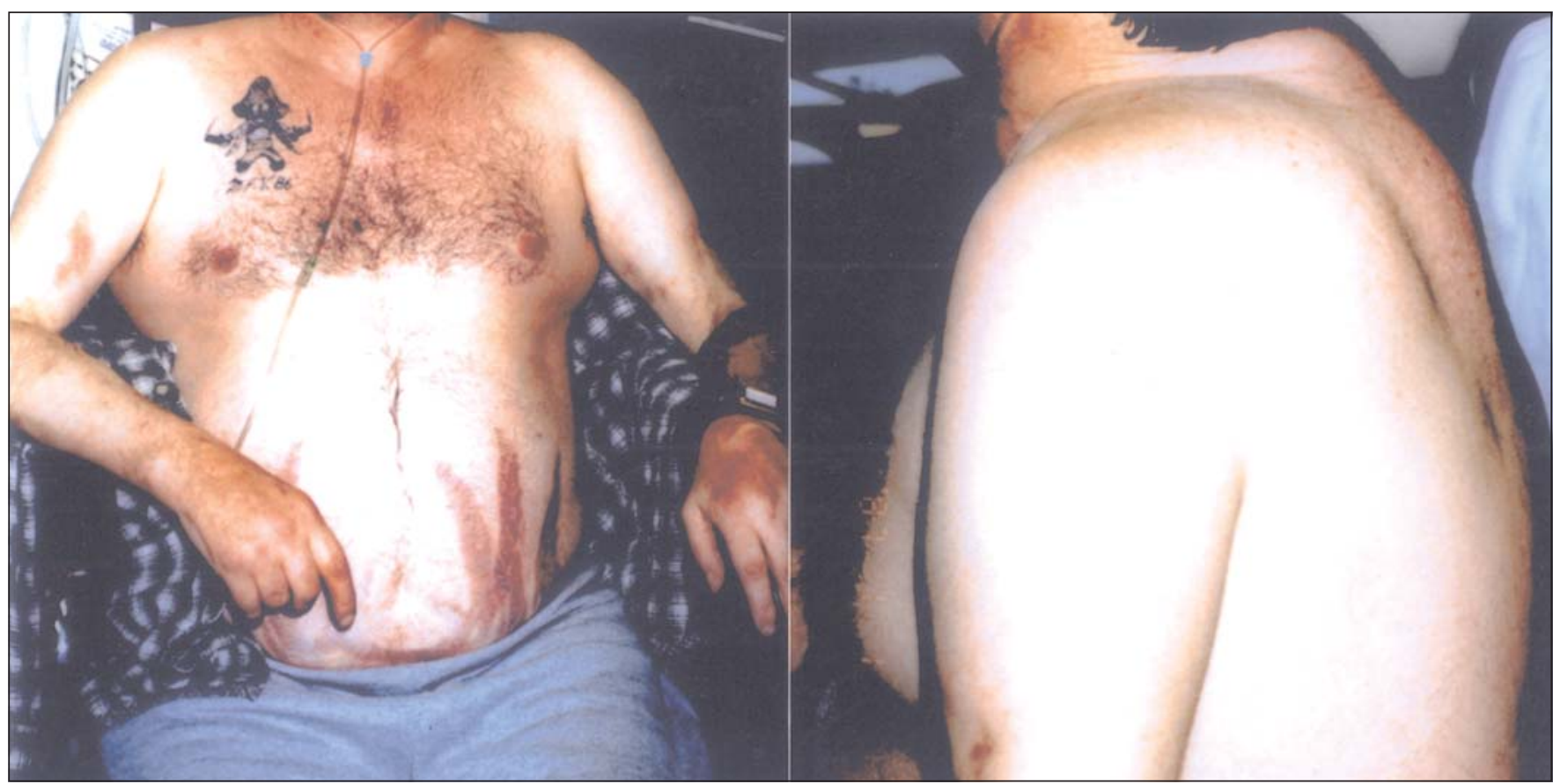

Figure 2) Protease inhibitor-associated lipodystrophy syndrome including abdominal obesity with striae, a buffalo hump and muscle wasting of the limbs in a 41-year-old male patient with human immunodeficiency virus infection

at presentation. He had a history of previous injection drug use, multiple female sexual partners and a tattoo. He was started on dual antiretroviral therapy, and when protease inhibitors became available in 1996, he was changed to a triple regimen including a protease inhibitor. His plasma viral load decreased to undetectable levels (fewer than 400 copies $/ \mathrm{mL}$ ), but by 1998 , the viral load had increased to 500,000 copies $/ \mathrm{mL}$. His regimen was altered, and he responded with an increase in CD4 cell count to 680 and an undetectable viral load (fewer than 50 copies $/ \mathrm{mL}$ ) (Figure 1).

From 1994 to 1998, his opportunistic infections included PCP, mycobacterial adenitis (smear-positive, culture-negative), multidermatomal herpes zoster, HIV retinopathy and recurrent bacterial pneumonias.

Following his episode of PCP in 1994, he developed progressive shortness of breath. He was a smoker with a 25 pack-year history. Previous occupational exposures included working in a sawmill and spray painting cars. He had two pet dogs but no bird exposure and no history of foreign travel. Although he had a history of injection drug use, he had never injected particulate matter, such as crushed pills. Although he had previous mycobacterial adenitis, his chest X-ray showed no evidence of pulmonary involvement. Pulmonary function tests (March 1996) revealed severe airflow obstruction (forced expiratory volume in $1 \mathrm{~s} 29 \%$ predicted, $15 \%$ improvement with bronchodilator use) with marked hyperinflation (residual volume $226 \%$ predicted) and a severe reduction in diffusion (39\% predicted). Expiratory reserve volume was markedly reduced. There was a significant response to bronchodilator. The patient was diagnosed with COPD with partial reversibility secondary to smoking, PCP, and possibly HIV infection (4) and injection drug use (5). Beginning in 1995, he was treated with inhaled corticosteroids, salbutamol, ipratropium and, later, salmeterol.

In June 1998, he had been noted to have lipodystrophy syndrome. He had abdominal obesity with striae, a buffalo hump and muscle wasting of his limbs (Figure 2). He had previously had only one short course of prednisone for a COPD exacerbation and was not thought to be cushingoid. Over the next year, his lipodystrophy worsened, as did his respiratory symptoms. By 1999, he was confined to a wheelchair and required home oxygen therapy. His arterial blood gases showed chronic respiratory acidosis with carbon dioxide retention ( $\mathrm{pH} 7.38, \mathrm{PCO}_{2} 52$, bicarbonate 31 ). A high resolution computed tomography scan of his chest (March 1999) showed confluent centrilobular emphysema, which was more severe in the upper lobes. In addition, there was increased adiposity in the mediastinum and upper anterior chest, thought to be a component of his lipodystrophy syndrome. In May 1999, all of his antiretroviral medications were stopped. It was thought that his thorax and abdominal obesity and muscle wasting might have been contributing to his worsening respiratory status, and that by stopping his antiretroviral medications, his pulmonary function would improve.

On May 14, 1999, he presented to hospital with confusion and respiratory distress, and was found to have hypercapneic hypoxemic respiratory failure $\left(\mathrm{pH} 7.30, \mathrm{PCO}_{2} 60\right.$, $\mathrm{PO}_{2}$ 45, bicarbonate 29). He required intensive care unit admission, intubation and ventilation. He was unable to be weaned from the ventilator despite multiple attempts. After 14 days in hospital, he developed a nosocomial pneumonia, and, despite aggressive care, he died. 


\section{DISCUSSION}

Although our patient had significant obstructive pulmonary disease causing morbidity and, ultimately, his death, we speculate that the lipodystrophy syndrome contributed to his outcome by increasing his abdominal girth, and causing adiposity of his mediastinum and upper chest. A dramatic worsening over a relatively short time in the severity of his respiratory symptoms coincided with the worsening lipodystrophy.

Increasing abdominal and thoracic fat compromise pulmonary function by several mechanisms including increasing the work of breathing, compromising respiratory muscle function, promoting small airway closure and increasing the risk of the development of obstructive sleep apnea/hypoventilation syndromes (6). Computed tomography has been used to provide a direct measurement of thoracic and abdominal fat, but the analysis of results is not well standardized. Patients with the lipodystrophy syndrome have an increased ratio of visceral adipose tissue to total adipose tissue when computed tomography scans are done at the level of the fourth lumbar vertebra. However, thoracic adiposity is not defined in this population (7).

Attempts to identify patients who are more likely to develop lipodystrophy are ongoing. Risk factors may include a longer duration of protease inhibitor therapy, and the combination therapy of ritonavir-saquinavir rather than indinavir alone (8). There appears to be no association between lipodystrophy and CD4 count, viral load, duration of HIV infection, other concomitant therapies or previous AIDS (9). The pathogenesis of the development of lipodystrophy is not well understood. It is likely that multifactorial etiologies, with combined endocrine and metabolic abnormalities, have profound effects on body fat distribution and insulin resistance (10).
In HIV-positive patients with COPD who are receiving highly active antiretroviral therapy, clinical status and pulmonary function tests should be monitored. Nonprotease inhibitor antiretroviral combinations, such as those containing the nucleoside analogue stavudine, have also been associated with the lipodystrophy syndrome; therefore, patients on any antiretroviral combination require monitoring (10). Regression of the lipodystrophy syndrome after stopping or changing therapy has not been documented uniformly, but it may take eight weeks for abdominal girth to be measurably reduced (11).

\section{REFERENCES}

1. Carpenter CC, Fischl MA, Hammer SM, et al. Antiretroviral therapy for HIV infection in 1998: Updated recommendations of the International AIDS Society USA panel. JAMA 1998;280:78-86.

2. Galli M, Polo R, Saint-Marc T, Walli R. Proposal for a clinic classification of morphological and metabolic alterations under ART. Antiviral Ther 2000;5(Suppl 5):57.

3. Tsiodras S, Mantzoros, C, Hammer S, Samore M. Effects of protease inhibitors on hyperglycemia, hyperlipidemia, and lipodystrophy: A 5-year cohort study. Arch Intern Med 2000;160:2050-6.

4. Kuhlman JE, Knowles MC, Fishman EK, Siegelman SS. Premature bullous pulmonary damage in AIDS: CT diagnosis. Radiology 1989;173:23-6.

5. Gurney JW, Bates FT. Pulmonary cystic disease: Comparison of Pneumocystis carinii pneumatoceles and bullous emphysema due to intravenous drug abuse. Radiology 1989;173:27-31.

6. Dantzker DR, MacIntyre NR, Bakow ED. Comprehensive Respiratory Care. Philadelphia: WB Saunders Company, 1995:331,810.

7. Safrin S, Grunfeld C. Fat distribution and metabolic changes in patients with HIV infection. AIDS 1999;13:2493-505.

8. Carr A, Samaras K, Burton S, et al. A syndrome of peripheral lipodystrophy, hyperlipidaemia and insulin resistance in patients receiving HIV protease inhibitors. AIDS 1998;12:F51-8.

9. Carr A, Samaras K, Chisholm DJ, et al. Abnormal fat distribution and use of protease inhibitors. Lancet 1998;351:1736. (Lett)

10. Saint-Marc T, Touraine J-L. 'Buffalo hump' in HIV-1 infection. Lancet 1998;352:319-20. (Lett)

11. De Luca A, Murri R, Damiano F, Ammassari A, Antinori A. 'Buffalo hump' in HIV-1 infection. Lancet 1998;352:320. (Lett) 


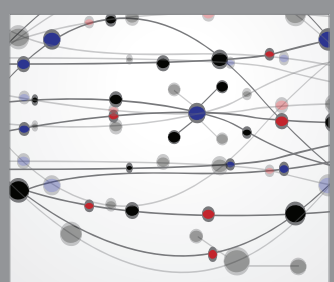

The Scientific World Journal
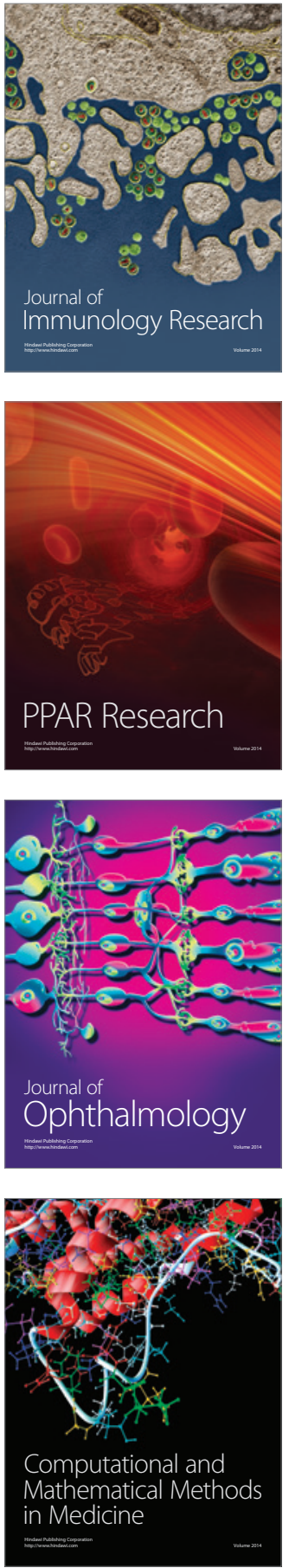

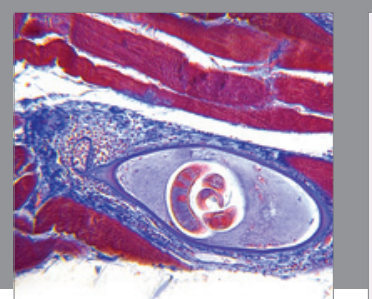

Gastroenterology Research and Practice

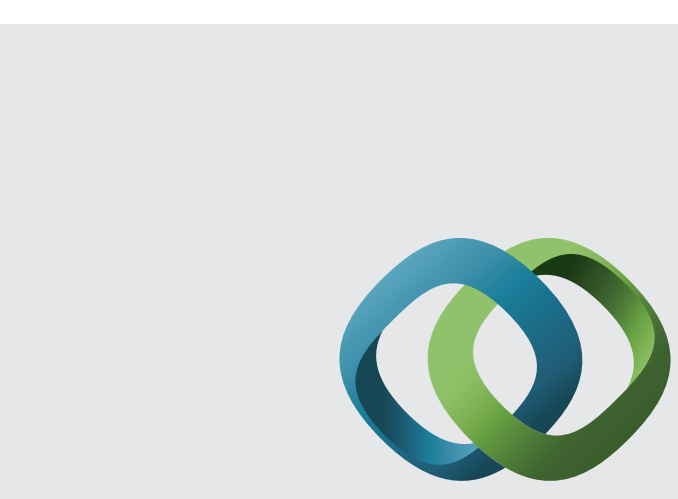

\section{Hindawi}

Submit your manuscripts at

http://www.hindawi.com
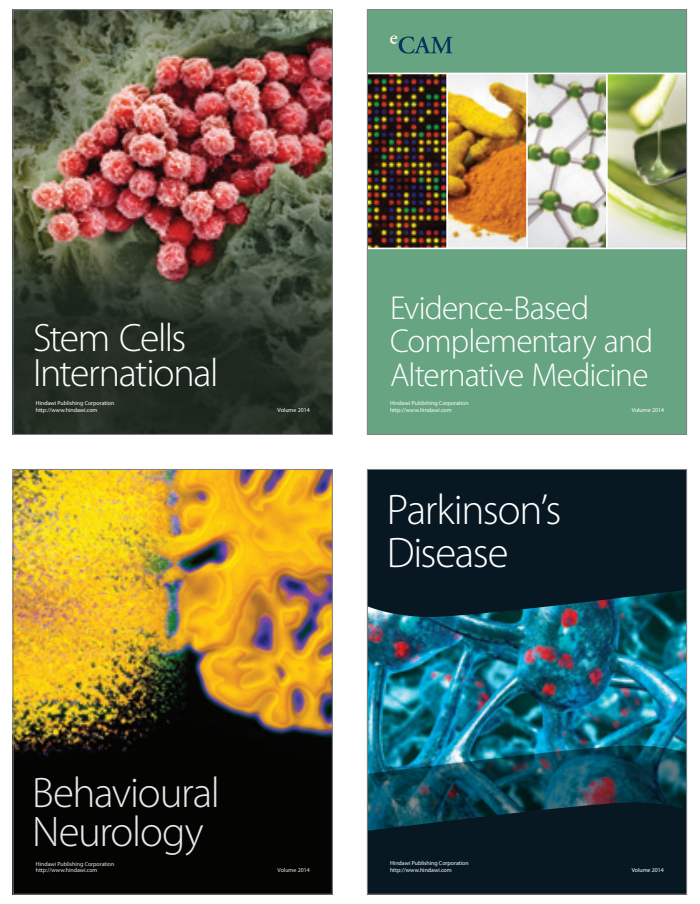
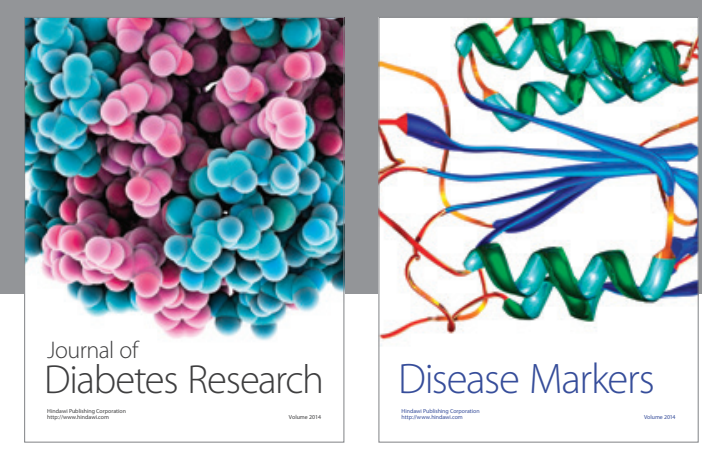

Disease Markers
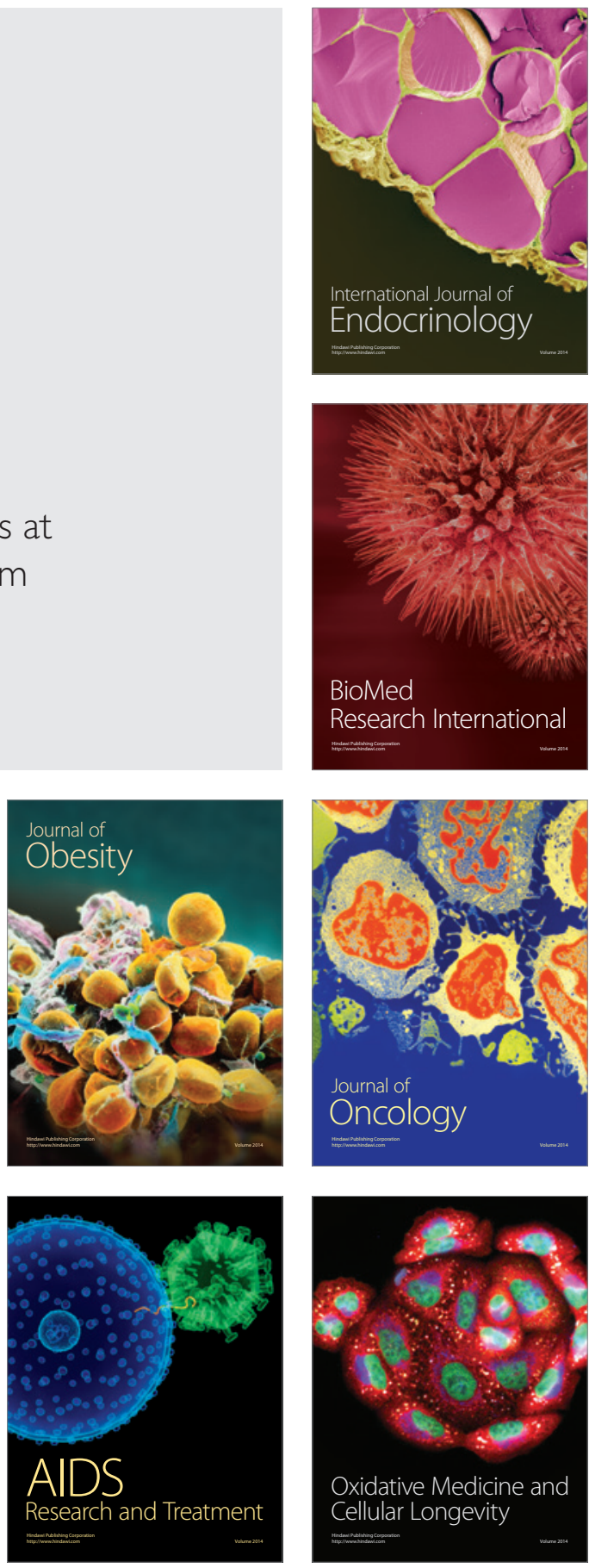